Article

\title{
Effects of Land-Use Characteristics on Transport Mode Choices by Purpose of Travel in Seoul, South Korea, Based on Spatial Regression Analysis
}

\author{
Byunghak Min ${ }^{1}$, Gunwon Lee ${ }^{2}$ and Seiyong Kim ${ }^{1, *}$ \\ 1 Department of Architecture, Korea University, 145, Anam-ro, Seungbuk-gu, Seoul 02841, Korea; \\ noahmin@korea.ac.kr \\ 2 Division of Architecture, Civil and Environmental Engineering, Hoseo University, 20, Hoseo-ro 79 beon-gil, \\ Baebang-eup, Asan-si 31499, Korea; gwlee@hoseo.edu \\ * Correspondence: kksy@korea.ac.kr; Tel.: +82-2-3290-3341
}

check for

updates

Citation: Min, B.; Lee, G.; Kim, S. Effects of Land-Use Characteristics on Transport Mode Choices by Purpose of Travel in Seoul, South Korea, Based on Spatial Regression Analysis. Sustainability 2021, 13, 1767. https:// doi.org/10.3390/su13041767

Received: 23 December 2020

Accepted: 29 January 2021

Published: 6 February 2021

Publisher's Note: MDPI stays neutral with regard to jurisdictional claims in published maps and institutional affiliations.

Copyright: (c) 2021 by the authors. Licensee MDPI, Basel, Switzerland. This article is an open access article distributed under the terms and conditions of the Creative Commons Attribution (CC BY) license (https:// creativecommons.org/licenses/by/ $4.0 /)$.

\begin{abstract}
The objective of this study was to identify the effects of land-use characteristics on the transport mode choices of people according to their purpose of travel. Land-use characteristics consisting of variables associated with density, diversity and accessibility were selected as independent variables. The volume of traffic entering each administrative neighborhood was extracted to establish travel data as the dependent variable. We compared and analyzed the results derived from ordinary least squares (OLS) analysis and spatial regression (SR) analysis. The results showed that the explanatory power of the SR model was higher than that of the OLS model. The results in this study reveal that the effects of land-use characteristics on travel show clear differences according to the transport mode, more so than according to the purpose of travel. Moreover, the results showed that an increase in the level of variables associated with density does not always facilitate the use of non-motorized or public transit modes, nor does it always deter the use of personal motorized modes. The findings in this study are significant in a knowledge-sharing context, as they present the effects of land-use characteristics on the volume of traffic in high-density cities, using Seoul as a case study.
\end{abstract}

Keywords: land-use characteristics; purpose of travel; transport modes choice; ordinary least squares analysis; spatial regression analysis

\section{Introduction}

Since industrialization began in the 18th century, rapid urbanization and suburbanization has spurred low-density development based on single land-use and has led to the horizontal sprawl of buildings [1,2]. Such urban sprawl has caused regions to be spatially separated and contextually divided, which has led to further increases in travel time and distance as people move between regions [2,3]. Due to increased travel distances, dependence on personal vehicles has risen in place of walking or using public transit, as the former reduces travel time and increases convenience. As a result of this change in transportation preferences, traffic congestion during commuting hours has become more severe in large-scale business districts, thereby exacerbating traffic problems [4-6].

Urban planning theories that emerged during the mid and late 20th century, such as compact city, new urbanism and smart growth, proposed guidelines to reduce the use of personal vehicles; such theories advocated for increased public transit use and walking in compact and mixed-use developments [7-9]. In this context, Jacobs opposed the vehicle-centric tenets of modernist urban planning and claimed that mixed land-use could promote walking, based on empirical evidence [10]. Using land for compact and mixed-use development can increase land-use efficiency by shortening travel distances or reducing inefficient travel. Moreover, convenience and active use of public transit could 
be promoted through transit-oriented development, which can ultimately reduce peoples' dependence on personal vehicles by shifting their preferences [11-15].

From early on, many studies collected empirical data to analyze the effects of mixeduse and high-density land-use methods designed to reduce personal vehicle dependency $[15,16]$. Certainly, the possibility of inconsistent results derived from researchers using different data or spatial range for analysis cannot be dismissed. However, most studies found that in cities with high-density or mixed-use land development, people had a higher tendency to use non-motorized modes of travel, such as walking or bicycling and were more likely to use public transit modes, such as buses or railways $[5,11,13,15,17]$. Such findings suggest that increased mixed-use of land can lower personal vehicle dependency by decreasing the frequency of travel using personal vehicles [17].

However, most of these studies focused on business travel to commute to and from work. Consequently, analysis of the effects of land-use characteristics on peoples' transport choices has been confined to a limited segment of travel purposes; the exclusion of nonbusiness travel from the existing body of research presents a knowledge gap that requires further study. When travel is divided by purpose, it can generally be divided into "business" and "non-business" travel [2]. Such classification is applied equally according to whether the traveler's choice of destination is voluntary or not. "Business" travel refers to travel with a limited choice of destination as the destination is fixed, such as work or school. In contrast, "non-business" travel refers to travel that allows the traveler to choose his or her destination freely, such as shopping or leisure activities. In this case, the traveler has the freedom to choose the destination and as a result, he or she chooses his or her destination by considering accessibility. Therefore, the effects of land-use characteristics on transport mode choices may differ between business and non-business travel. Despite this, there have been relatively few empirical studies that have analyzed the effects of land-use characteristics on transport mode choices, including non-business travel [17-19].

Accordingly, the objective of this study was to analyze the effects of land-use characteristics on transport mode choices for all travel purposes by conducting a case study in Seoul, South Korea. For this study, each administrative neighborhood in Seoul was analyzed. Seoul was selected as a representative high-density city because it has been characterized by ongoing large-scale development since the 1970s. This study also examined the suitability of various spatial analytical techniques for this type of inquiry. The results of this study are significant in terms of knowledge sharing; its findings can serve as a reference in the planning of other high-density metropolitan cities. Its findings can also be utilized as basic justification for establishing a pedestrian-friendly city and as guidance for land-use planning. In addition, this study adds value by providing an analytical framework that is suitable for analyzing travel data (including walking travel) by comparing it with the results of linear regression analysis using the ordinary least squares method (OLS) and spatial regression analysis that considers spatial autocorrelation.

\section{Literature Review and Hypothesis}

\subsection{Literature Review}

The impact of compact and mixed-use development in cities on the relationship between land-use characteristics and human traffic has been actively studied since the 1980s, with much of this research based on major cities in the United States (US) [15,20,21]. Researchers in the US have reached a consensus that increasing the compactness and diversity of land-uses in cities can reduce personal vehicle travel, as well as promote walking or use of public transit [16]. Specifically, it has been found that when land-use in suburban areas was zoned for mixed-use with a mixture of commercial buildings, rather than single-use zoning, consisting of mostly office buildings, traffic congestion during commuting hours was alleviated; it was found that travel to and from work by nonmotorized modes (such as walking or bicycling) increased and that travel using a personal vehicle decreased [1,22]. Other researchers found that when an imbalance exists between the number of businesses and homes in an area such that there are more households than 
jobs, that travel by walking or bicycling declines and highway congestion increases due to increased use of personal vehicles. When such conditions persist for a long time, the average commute distance also increases [11,23]. Frank and Pivo (1994) identified that with high- density and mixed land-use, the use of public transit and pedestrian traffic volume both increase, whereas the use of personal vehicles decreases [13]. In particular, pedestrian traffic is most sensitive to population density; when factors other than the city type are controlled, mixed land-use at the origin and destination of travel was found to only affect pedestrian travel related to travel of the business variety [13].

During the 1990s, numerous studies investigated the effects of land-use characteristics by classifying them into the "3Ds" (i.e., density, diversity and design) [17,24]. These studies considered the interactions of land-use mix and pedestrian-friendly environmental design and identified that density, diversity and pedestrian-centric design elements all facilitate non-motorized modes of transport; in particular, they found that compact development and the distance of neighborhood living facilities from homes affected the transport mode choices for commuting to and from work [17]. Meanwhile, with respect to walking, the origin/destination $(\mathrm{O}-\mathrm{D})$ of travel and characteristics of the travel route that connects the two are just as important as the elements of the 3Ds. Specifically, other characteristics, such as the length of the travel route, total length of the pedestrian walkway in the nearby area and the residential block size were proven to be important elements that affect walking [24].

Increased travel volume of non-motorized modes is an indication of a relative decrease in people traveling by car. If non-motorized modes of transport increase during commute hours, this can alleviate traffic congestion; this can in turn lead to economic benefits from increased efficiency in parking spaces and environmental benefits, such as reduced noise and improved air quality [25-28].

On the other hand, studies that analyzed European urban areas derived results that contradict those of studies in US urban areas. A study in Ghent, Belgium found that mixed land-use affected the walking activities of females but that the density of urban development had no effect on walking activities; this finding contradicts existing studies in the US that reported that urban densification increased walking activities [29,30]. To summarize these precedent studies, most of those conducted in the US showed decreased travel by personal motorized mode and increased travel by walking or use of public transit for commuting when land-use was more compact and mixed [15,16]. However, just as some studies demonstrated that densification of land-use is not necessarily a factor that contributes to increased walking [29,30], it can be inferred that the effects of landuse characteristics on travel could be different depending on the physical conditions of urban areas.

Most researchers in this field of study used the OLS analytical technique to analyze the effects of land-use characteristics on travel [29,31-34]. It is important to note that travel is not only affected within the unit space being analyzed but that it can also be affected by the land-use characteristics of neighboring spaces [35-37]. However, few studies take this into account; most conduct regression analyses without considering the spatial autocorrelation that may exist between neighboring unit spaces. The existence of a spatial autocorrelation means that a spatial influence is present in the dependent variables [38]. Therefore, it is necessary to determine if spatial autocorrelation is present and if so, to control for its spatial influence to ensure accurate results [38]. Accordingly, this study investigated the need for spatial regression (SR) analysis by diagnosing the presence of spatial autocorrelation of dependent variables. This was done to determine whether spatial influence needs to be controlled for when analyzing the relationship between land-use characteristics and mode of travel choice. The study also compared SR analysis to the commonly used OLS analysis to investigate the performance of this analytical framework.

\subsection{Hypothesis}

The following research problems were identified based on a review of existing studies: 
- In the diagnosis of spatial autocorrelation in the dependent variable (i.e., travel volume), there is a high likelihood of identifying the presence of spatial autocorrelation.

- If spatial autocorrelation exists, then there is a high likelihood that the results from a SR analysis will have a higher explanatory power than those from a conventional OLS analysis.

- If non-business travel is analyzed together with business travel (the latter of which was mostly examined in existing studies), then a difference between the mode of transport that is chosen for the two purposes of travel is likely to be found.

- Compactness and mixed-use zoning may not always be factors that cause increased pedestrian traffic volume or use of public transit.

Based on these research problems, the hypotheses investigated in this study are as follows:

1. The dependent variable (i.e., travel volume) is expected to be affected by spatial autocorrelation and the results of subsequent analyses will show that SR analysis has higher explanatory power than conventional OLS analysis.

2. When the effects of land-use characteristics on transport mode choices are analyzed with the purpose of travel divided into business and non-business types, there will be differences in the variables associated with land-use characteristics that affect these two different purposes of travel; it is expected that land-use characteristics will have a greater effect on non-business travel than on business travel.

3. Even with higher density, diversity and accessibility (the variables associated with land-use characteristics), pedestrian traffic volume and use of public transit will not always increase.

\section{Material and Methods}

\subsection{Analytical Models and Variables}

\subsubsection{Establishment of Independent Variables}

The variables used in this study were divided into independent variables (i.e., variables associated with land-use characteristics) and a dependent variable (i.e., travel volume). The selection of the independent variables was based on those used in previous studies. Most early studies that analyzed the relationship between land-use characteristics and travel volume only examined the impact of density $[1,21]$. However, a more detailed analysis of the built environment can be conducted by dividing land-use characteristics into the 3Ds (density, diversity and design) for analyzing travel that occurs within a small spatial range, such as walking $[12,17,39]$. In addition to the 3Ds, other researchers added distance to transit and destination accessibility (2Ds) as variables and demonstrated the importance of accessibility as a variable of land-use characteristics that affects travel [15]. Moreover, it has also been suggested that the degree of development or demographics should also be considered [16].

Data acquisition constraints and the review of variables associated with land-use characteristics discussed in previous studies led us to divide the land-use characteristics into three variables (i.e., density, diversity and accessibility); we further divided these into a total of 12 sub-independent variables. Density is a characteristic of land-use that represents the density of the area for buildings and populations and includes residential density, commercial density, population density and employment density $[11,13,17,22]$. Residential density and commercial density respectively mean the gross floor area (GFA) of residential, commercial and neighborhood living facilities. Unlike residential and commercial density calculated by GFA, population density and employment density were calculated through the number of people and each represents the number of residents and the number of employees $[11,17,22]$.

Diversity represents the characteristics related to the degree of mixing and distribution of land-use [17]. The entropy index, the non-reflection index, the work week balance, the residential-non-residential index and the industrial mix were selected as variables. 
For the selected diversity-related variables, two issues were considered when using the entropy index. The first issue concerned the settings for what is being measured. The measurement method used in this study for mixed-use could be divided into area by the land-use type and GFA by use of a building. Regarding land-use and use of a building, determining which factor can accurately reflect the actual purpose of a lot becomes an important criterion for selecting the subject to be measured [40,41]. While most researchers calculate the entropy index based on land-use area $[1,6,17]$, in this study, it was evident that it would be difficult to determine if the land-use type reflects the way that the lot is actually used; this is because the Building Act in South Korea has allowed uses of a building that is inconsistent with the characteristic of land-use [42]. For example, if the use of a building is a 'class 1 neighborhood living facilities,' then the building is permitted under 21 zoning types, including residential areas and commercial areas. Moreover, if the use of a building is a 'detached houses,' then the building is permitted under all types of zoning, except for exclusively industrial areas. Accordingly, there may be buildings in locations with dissimilar characteristic of land-use designated for a lot; thus, it is difficult to accept that land-use accurately reflect how the lot is actually used. The use of a building is a more accurate metric in reflecting how a lot is actually used; thus, in this study, we calculated the entropy index through uses of a building [43].

The second issue is the measurement method. There are two methods for measuring entropy: generalized entropy as shown in Equation (1) and mean entropy, as shown in Equation (2) [17]. Although both methods share the same measurement principle, they differ depending on whether the area being measured is further divided or not.

$$
\text { (Entropy Index })=-\sum_{i=1}^{n} \frac{P_{i} \ln P_{i}}{\ln n} .
$$

Here, $P_{i}$ is the proportion of building-use category $i$ within an area and $n$ is the number of building-use categories.

$$
\text { (Mean Entropy Index })=-\frac{1}{K} \sum_{i}^{K} \sum_{j=1}^{n} \frac{P_{i j} \ln P_{i j}}{\ln n} .
$$

In Equation (2), $P_{i j}$ is the proportion of building-use category $j$ within a lot $i, n$ is the number of building-use categories and $K$ is the number of divided lots within an area.

The generalized entropy index is calculated by the proportion of area by use category within an entire area without any division. To calculate mean entropy, the area being measured is divided and the entropy index for each unit space is measured, after which the mean entropy index of each unit space is calculated and that value is considered the entropy index for the entire area [41]. Although few studies have used mean entropy [41], the unit area analyzed is often an entire city, whereby the entire area is divided into areas with a radius of approximately $800 \mathrm{~m}$ (half a mile) to measure the entropy of the city $[41,44]$. The unit area used in the present study was administrative neighborhoods with an average size of approximately $1.42 \mathrm{~km}^{2}$. The area was smaller than the circular unit space area $\left(2.01 \mathrm{~km}^{2}\right)$ divided for mean entropy measurements; therefore, it was not necessary to further divide the unit space. Accordingly, the entropy index by administrative neighborhood was calculated based on the generalized entropy measurement method [43].

The dissimilarity index is calculated as shown in Equation (3) (i.e., another diversityrelated variable) and is designed to measure the similarity between neighboring elements $[36,40]$. In this study, the dissimilarity index was measured based on similarity in land-use between neighboring unit spaces:

$$
\text { (Dissimilarity Index })=\frac{1}{K} \sum_{k=1}^{K} \sum_{j=1}^{J} \frac{D_{j k}}{J},
$$


where $K$ is the number of grid cells within an area, $D_{j k}=1$ if the building-use category of neighboring (i.e., abutting or caddy-corner) grid-cell differs from grid-cell $j$ (otherwise $D_{j k}=0$ ) and $J$ is the number of neighboring cells ( 8 if the area is divided into grid cell).

Generally, the entropy index tends to be used more often due to the calculation method being less complicated than that of the dissimilarity index [40,45,46]. However, the entropy index reflects how evenly each use category is distributed within the entire unit area. On the other hand, the dissimilarity index measures the dissimilarity in land-use between neighboring unit spaces after dividing the unit area into grid cells. Ultimately, the dissimilarity of the unit area is calculated as the average dissimilarity to indicate how land-use differs and is distributed within that area [17,47].

Figure 1 presents an example to explain the difference between the entropy index and dissimilarity index. In Figure 1, both Areas A and B have the same area by land-use (i.e., residential use, commercial use, industrial use and green space); however, they differ in the distribution of use areas. In this case, since the area by land-use is the same, the entropy index for both areas is 1 . Computation of the dissimilarity index, however, shows the central " $C$ " plot within a red circle in Area A receives 5/8 (=0.625) point for having five of its eight neighboring plots" uses as distinct, whereas, the central " $\mathrm{C}$ " plot within a red circle in Area $B$ receives 6/8 $(=0.75)$ point since six of the surrounding eight plots are designated by a different land-use. As a result, Area B would have a higher dissimilarity index $(=0.796)$ than Area A (=0.356) due to more different types of land-use in the neighboring plots.

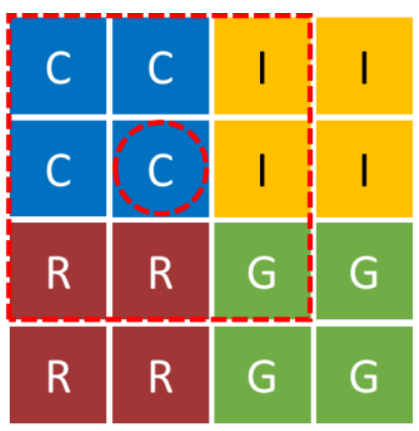

$<$ Area $A>$

$$
\begin{gathered}
\text { Entropy }=1.000 \\
\text { Dissimilarity }=0.356
\end{gathered}
$$

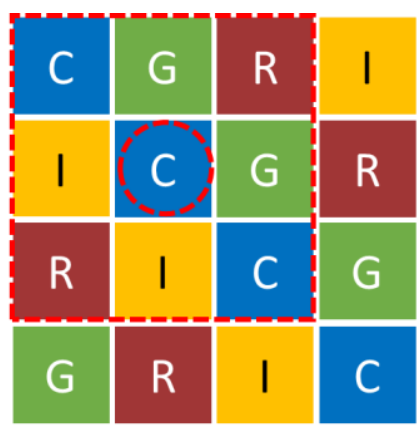

$<$ Area B >

$$
\begin{gathered}
\text { Entropy }=1.000 \\
\text { Dissimilarity }=0.796
\end{gathered}
$$

Figure 1. Differences in entropy and dissimilarity indices according to land-use patterns.

As shown in Figure 1, the dissimilarity index takes on a different meaning from the entropy index in that it reflects the degree of mixed-use and the categorization of land-use. Accordingly, both indices were selected as diversity-related variables in this study [43]. The equation for calculating the dissimilarity index is the same as the equation used in previous studies [17]. For this study, the grid was set to $20 \mathrm{~m}$ to include buildings within the grid and took into consideration the average size of buildings.

The job-housing balance index is an index representing the ratio between the number of residents and the number of workers in the region and it is an indicator of diversity that has been used earlier since the formula is simple $[11,48,49]$. The same number of residents and employees means that Job-housing balance index has a maximum value which is 1 and a value close to 0 means that the number of residents or employees is large [11,23,48].

The residential-non-residential index refers to the difference in share between the GFA of residential facilities and the GFA of non-residential facilities in the area [50]. The range of the calculated value is between 0 and 1 and the larger the difference in GFA between residential and non-residential facilities, the closer the value of the residentialnon-residential index is to 0 . If the difference in occupancy between residential and non-residential facilities is large, the value approaches 0 , which means that single land-use 
is high. Conversely, moving closer to 1 means that the mixed land-use is achieved by a combination of residential and non-residential facilities [50].

The industry mixture index is an index that evaluates the distribution of industries within a region and represents the ratio of workers in a specific industry to the total industry [51-53]. In this study, the degree of the index was calculated for the service industry. If the calculated value is close to 1 , it means that the number of service workers in the region is large, which means that industries are diversely distributed [51,53].

Accessibility is a land-use characteristic that represents accessibility to the area and in this study, accessibility to bus stations, total integration and local integration were selected as accessibility variables. The accessibility to bus stations is an indicator of accessibility to each administrative neighborhood through the bus and the greater the number of bus routes and stops passing through each administrative neighborhood, the better accessibility is. The accessibility measurement was calculated as the sum of the number of bus routes stopping at each stop located in each administrative neighborhood [53].

The integration index is a concept originating from space syntax. It measures the connectivity of streets through the connected relationship between the axis lines of the urban street network [54]. A higher degree of integration refers to better connection with a relatively large number of streets. In this study, the degree of integration was set as a variable by dividing the global integration for the entire Seoul area $(n=n)$ and the local integration for microspace $(n=3)$ [54].

The data used to establish each variable were provided by government agencies; specifically, resident registration population data was provided by the Ministry of Interior and Safety and data on the number of workers by industry, property tax ledger, list of bus routes and road networks were provided by Statistics Korea and the Seoul Metropolitan Government. Definitions of independent variables are given in Table 1.

Table 1. Definitions of independent variables.

\begin{tabular}{|c|c|c|c|}
\hline & Independent Variable & & Definition \\
\hline \multirow{4}{*}{ Density } & Residential density & $X_{1}$ & GFA * of residential facilities \\
\hline & Commercial density & $X_{2}$ & GFA of commercial and neighborhood facilities \\
\hline & Population density & $X_{3}$ & Number of populations \\
\hline & Employee density & $X_{4}$ & Number of employees \\
\hline \multirow{5}{*}{ Diversity } & Entropy index & $X_{5}$ & $-\sum_{j=1}^{n} \frac{P_{i j} \ln P_{i j}}{\ln n}$ \\
\hline & Dissimilarity index & $X_{6}$ & $\prod_{K}^{1} \sum_{k=1}^{K} \sum_{j=1}^{J} \frac{D_{j k}}{J}$ \\
\hline & Job-housing balance index & $X_{7}$ & $\begin{aligned} & \quad \frac{R_{i}}{E_{i}}\left.\text { if } E_{i} \geq R_{i}\right) \text { or } \frac{E_{i}}{R_{i}}\left(\text { if } E_{i} \leq R_{i}\right) \\
& R_{i}=\text { Number of residents in administrative neighborhood } i \\
& E_{i}=\text { Number of workers in administrative neighborhood } i\end{aligned}$ \\
\hline & $\begin{array}{l}\text { Residential-non-residential } \\
\text { index }\end{array}$ & $X_{8}$ & $\begin{array}{c}1-\left|\frac{\left(R_{i}-N R_{i}\right)}{\left(R_{i}+N R_{i}\right)}\right| \\
R_{i}=\text { GFA of residential buildings in administrative neighborhood } i \\
N R_{i}=\text { GFA of non-residential buildings in administrative neighborhood } i\end{array}$ \\
\hline & Industrial mixture index & $X_{9}$ & $\begin{array}{c}\text { (Number of employees in the tertiary industry) } \div \text { (Total number of } \\
\text { employees })\end{array}$ \\
\hline \multirow{3}{*}{ Accessibility } & Accessibility to bus station & $X_{10}$ & $\begin{array}{c}\text { Sum of the number of bus lines for each station in administrative } \\
\text { neighborhood }\end{array}$ \\
\hline & Global integration & $X_{11}$ & Integration value of street network $(\mathrm{n}=\mathrm{n})$ \\
\hline & Local integration & $X_{12}$ & Integration value of street network $(n=3)$ \\
\hline
\end{tabular}




\subsubsection{Establishment of Dependent Variable}

The dependent variable was divided broadly into business and non-business travel (defined depending on the purpose of travel); mode of transport was divided as either non-motorized, public transit or personal motorized modes, depending on public access to the transport mode and whether or not a motorized vehicle was used. Accordingly, six trip models based on the purpose of travel and transport mode were established, as shown in Table 2.

Table 2. Six trip models based on the purpose of travel and transport mode.

\begin{tabular}{|c|c|c|c|}
\hline \multirow{2}{*}{\multicolumn{2}{|c|}{ Division }} & \multicolumn{2}{|c|}{ Purpose of Travel } \\
\hline & & Business & Non-Business \\
\hline \multirow{3}{*}{ Transport mode } & Non-motorized & $\begin{array}{l}\text { Business trip by non-motorized modes } \\
\text { (Model 1) }\end{array}$ & $\begin{array}{l}\text { Non-business trip by non-motorized } \\
\text { modes (Model 2) }\end{array}$ \\
\hline & Public transit & $\begin{array}{c}\text { Business trip by transit modes } \\
\text { (Model 3) }\end{array}$ & $\begin{array}{c}\text { Non-business trip by transit modes } \\
\text { (Model 4) }\end{array}$ \\
\hline & Personal motorized & $\begin{array}{l}\text { Business trip by personal motorized } \\
\text { modes (Model 5) }\end{array}$ & $\begin{array}{l}\text { Non-business trip by personal } \\
\text { motorized modes (Model 6) }\end{array}$ \\
\hline
\end{tabular}

With respect to the data for each trip model, the study used O-D data from the household travel diary survey conducted by the Metropolitan Transportation Authority. These O-D data provide information about the transport mode used, purpose of travel and O-D of daily travel by all household members that were randomly sampled within the national capital region.

This study used 283,093 O-D data from 2010 to construct the trip models. Since the spatial unit that comprises the O-D data is "administrative neighborhood," the spatial unit in this study was also set to administrative neighborhood. Subsequently, the volume of traffic entering each administrative neighborhood was classified according to the purpose of travel and transport mode to derive the trip models. However, because the return leg of travel for "returning home" and "returning to work" repeat the same route as the outgoing leg of travel, such travel is unaffected by the land-use characteristics. Accordingly, travel for "returning home" and "returning to work" were excluded from the O-D data and data with destinations identified as 424 administrative neighborhoods in Seoul (i.e., the spatial range in this study) were sampled.

The O-D data were divided into eight different purposes of travel other than those previously excluded (i.e., "returning home" and "returning to work"), which consisted of: "to work," "to school," "for business," "for shopping," "for leisure," "to academy," "sendoff," and "others." Of these, "send-off" and "others" that lacked clear information regarding the purpose of travel were also excluded from the analysis set. Among the remaining purposes of travel, types of travel with limited or no choice due to the traveler having a fixed destination, such as "to work," "to school," and "for business" were categorized as business travel, whereas types of travel that allowed the traveler to freely choose the destination, such as "for shopping," "for leisure," and "to academy," were categorized as non-business travel.

The O-D data were also divided into a total of 18 transport modes. Among these, the "other" mode (i.e., with an unclear transport mode) was excluded from the analysis set. "Taxi" presents a unique case, in that it could be viewed as a public-use mode since it is not a personally owned means of transport or "taxi" could be seen as being limited to personal use and could therefore be viewed as a similar transport mode as "car/car-sharing;" for this study, "taxi" was categorized under the personal motorized mode. Categorization according to the aforementioned purposes of travel and transport modes and data corresponding to each category are shown in Table 3.

This study used ESRI ArcMap 10.0, DepthMap 10.14, GeoDa 9.3 and IBM SPSS Statistics 21 for data construction and spatial statistical analysis. All data were processed 
relative to 424 administrative neighborhoods in Seoul. Descriptive statistics of independent and dependent variables are shown in Table 4.

Table 3. Classificatory criterion of purposes of travel and transport modes.

\begin{tabular}{|c|c|c|}
\hline \multicolumn{2}{|c|}{ Division } & \multirow{3}{*}{$\begin{array}{c}\text { O-D Data Type } \\
\text { To work, to school, for business } \\
\text { To academy, for shopping, for leisure }\end{array}$} \\
\hline Purnece of travel & Business & \\
\hline Purpose or travel & Non-business & \\
\hline \multirow{3}{*}{ Transport mode } & Non-motorized & Walk, bicycle \\
\hline & Public transit & $\begin{array}{l}\text { Local bus, intercity bus, town bus, metro bus, express bus, other buses, } \\
\text { subway, railway train, KTX* }\end{array}$ \\
\hline & Personal motorized & Car (including car-sharing), taxi, motorcycle \\
\hline
\end{tabular}

*: Korea Train Express.

Table 4. Descriptive statistics of each variable.

\begin{tabular}{|c|c|c|c|c|c|}
\hline \multicolumn{2}{|r|}{ Variable } & \multirow{2}{*}{$\begin{array}{c}\text { Mean } \\
0.771\end{array}$} & \multirow{2}{*}{$\frac{\text { SD }}{0.400}$} & \multirow{2}{*}{$\begin{array}{c}\text { Min } \\
0.046\end{array}$} & \multirow{2}{*}{$\begin{array}{c}\text { Max } \\
2.779\end{array}$} \\
\hline & $X_{1}$ & & & & \\
\hline & $X_{2}$ & 0.390 & 0.370 & 0.014 & 3.649 \\
\hline & $X_{3}$ & 24,322 & 9014 & 1257 & 52,199 \\
\hline & $X_{4}$ & 8995 & 13,759 & 40 & 129,339 \\
\hline & $X_{5}$ & 0.559 & 0.165 & 0.070 & 0.982 \\
\hline Independent & $X_{6}$ & 0.253 & 0.085 & 0.017 & 0.472 \\
\hline \multirow[t]{8}{*}{ Variables } & $X_{7}$ & 0.301 & 0.223 & 0.016 & 0.988 \\
\hline & $X_{8}$ & 0.642 & 0.236 & 0.039 & 0.997 \\
\hline & $X_{9}$ & 0.864 & 0.089 & 0.505 & 0.998 \\
\hline & $X_{10}$ & 75 & 56 & 2 & 507 \\
\hline & $X_{11}$ & 0.625 & 0.088 & 0.368 & 0.806 \\
\hline & $X_{12}$ & 1.956 & 0.351 & 0.963 & 2.926 \\
\hline & Travel volume in Model 1 & 144 & 76 & 3 & 401 \\
\hline & Travel volume in Model 2 & 76 & 42 & 2 & 250 \\
\hline \multirow{4}{*}{$\begin{array}{l}\text { Dependent } \\
\text { Variables }\end{array}$} & Travel volume in Model 3 & 211 & 301 & 9 & 2372 \\
\hline & Travel volume in Model 4 & 54 & 76 & 0 & 907 \\
\hline & Travel volume in Model 5 & 145 & 172 & 4 & 1798 \\
\hline & Travel volume in Model 6 & 38 & 34 & 0 & 225 \\
\hline
\end{tabular}

\subsection{Diagnosis of Spatial Autocorrelation}

Spatial data obtained based on political and administrative districts not only contain information about the raw data themselves but also information about geographical space. Many previous models used for analyzing such spatial data do not consider the factor called "space" contained in these data and assume that data are randomly distributed throughout the given space [55]. When spatially-referenced data are analyzed using the traditional linear analytical methods, which assume that the variables are random and that error terms are independent and share the same distribution, spatial dependence and interaction, which are characteristics of many socioeconomic, demographic and natural phenomena that appear in space, cannot be controlled [56].

Accordingly, this study used the global Moran's I for diagnosis of spatial autocorrelation between variables prior to conducting the regression analysis. The global Moran's I is a calculated value used to determine clustering or dispersion of all elements within a spatial range [57]. A value close to -1 indicates even distribution in space due to different attributes between neighboring objects, whereas a value close to 1 indicates clustering in space due to similar attributes between neighboring objects. Meanwhile, a value close to 0 indicates random dispersion with no similar attributes between neighboring objects. If the Moran's I value calculated from the trip model is significant, then the results could be interpreted as the travel of that model being spatially influenced by administrative neighborhoods that 
neighbor the destination. In such cases, analysis must be conducted using SR analysis that controls the spatial influence of neighboring administrative neighborhoods [38].

When the presence of spatial autocorrelation was diagnosed based on calculated global Moran's I values by the queen method for each trip model, all types of trip models showed a significance probability of $<0.001$, as shown in Figures 2 and 3; this confirmed the existence of spatial autocorrelation. This means that because the dependent variable is spatially autocorrelated, the assumption of random distribution that is made by a general OLS regression analysis will create a bias in parametric estimates. Consequently, this study used SR analysis; however, general OLS analysis was also used to compare the models' explanatory power. SR analysis was carried out by entering all independent variables within the model into the analysis.
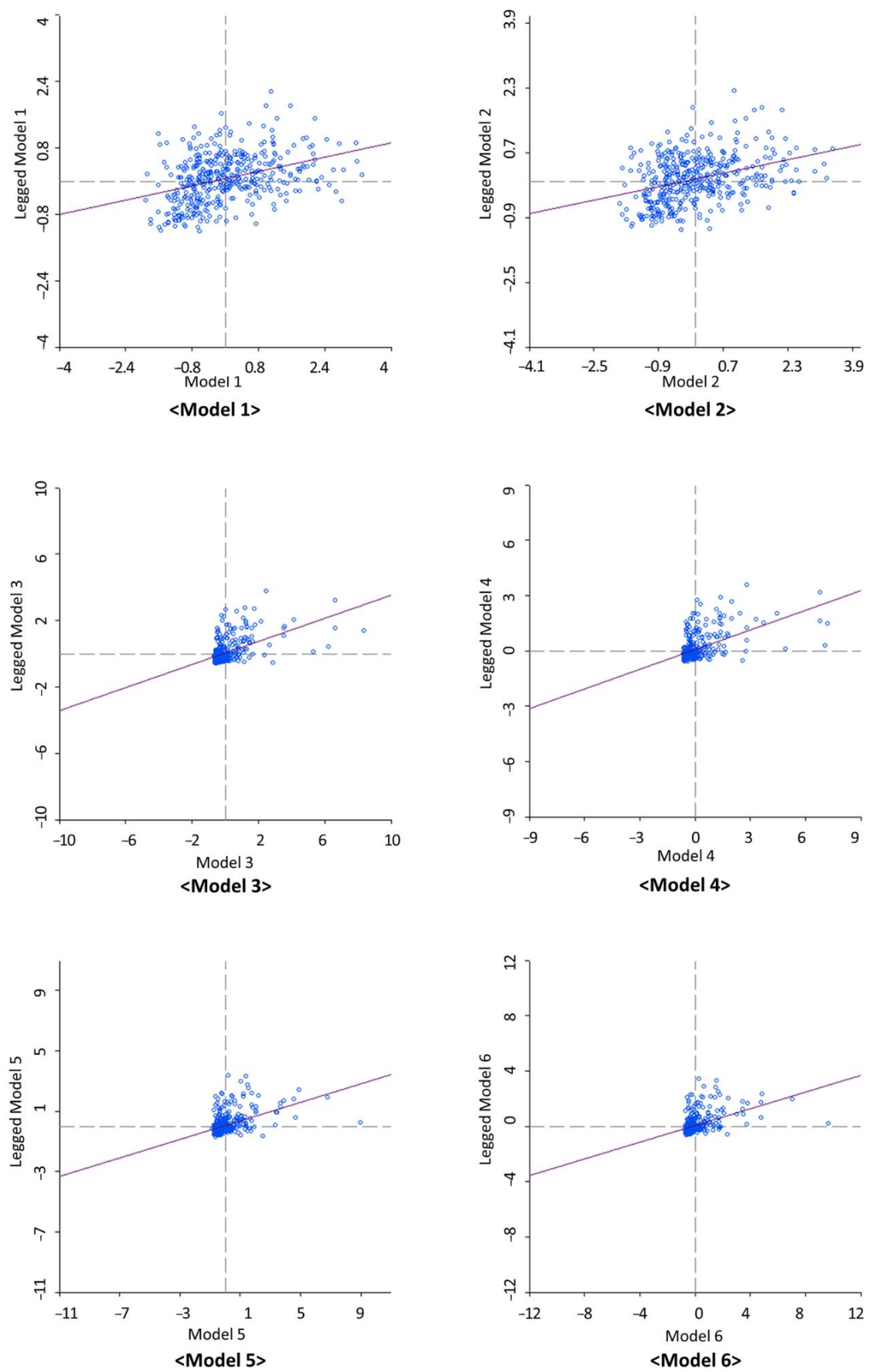

Figure 2. Global Moran's I scatter plot by trip model. 


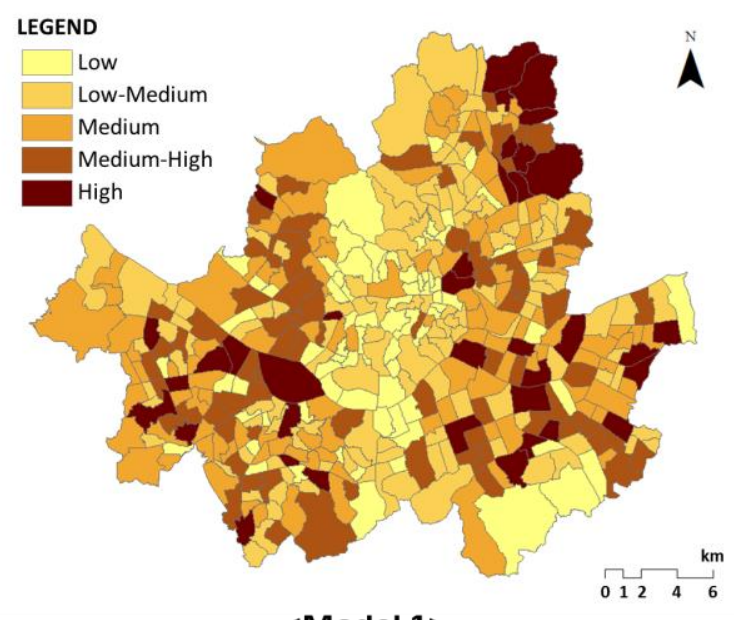

<Model 1>

Global Moran's I = 0.217***

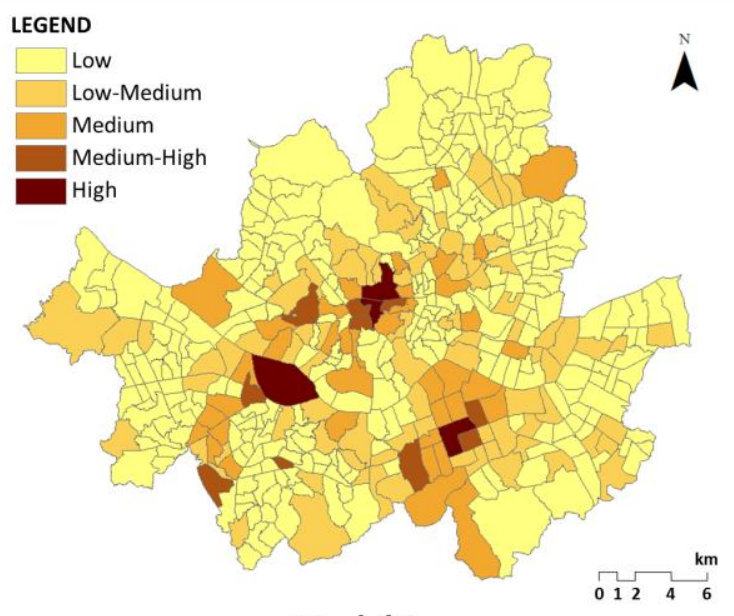

$<$ Model 3>

Global Moran's I = 0.347***

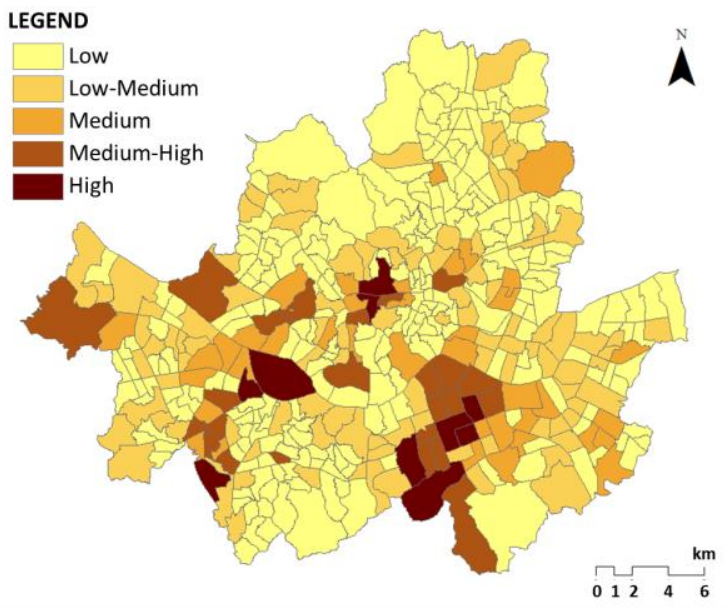

<Model 5>

Global Moran's I = 0.307***

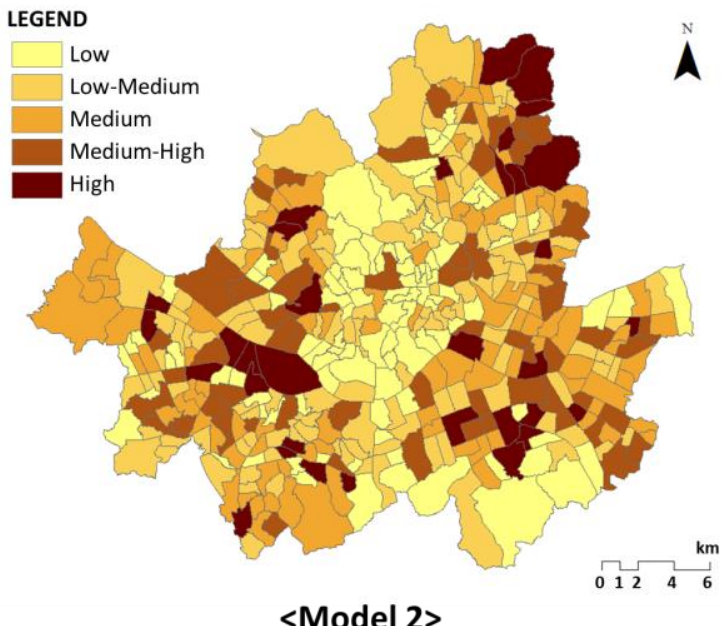

Global Moran's I $=0.207^{* * *}$

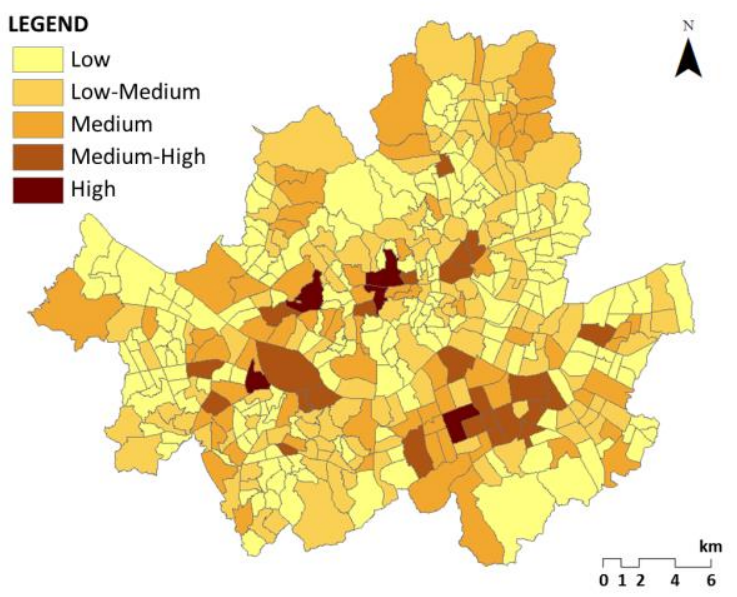

<Model 4>

Global Moran's I = 0.356***

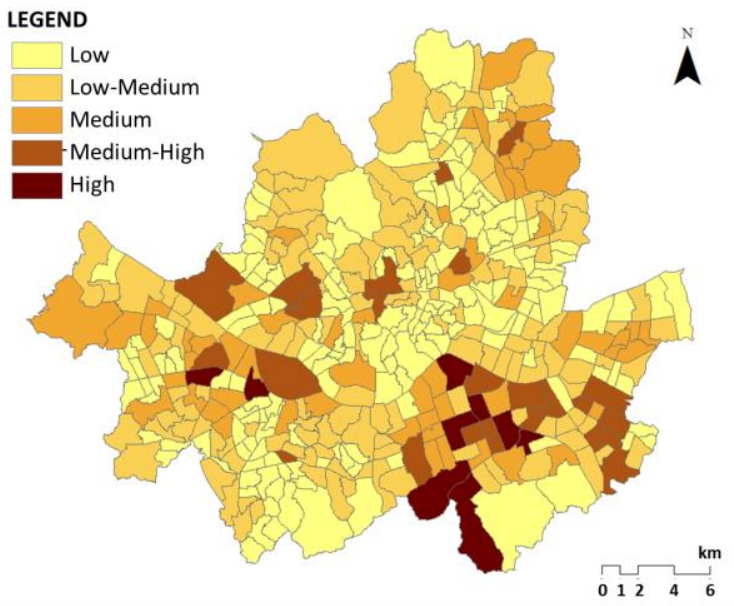

<Model 6>

Global Moran's I = 0.302***

Figure 3. Global Moran's I and travel distribution by trip model. 
Next, the study tested the 12 independent variables that were selected for multicollinearity to determine whether the prerequisites for regression analysis were satisfied. Results of the OLS regression analysis showed that when all 12 variables were applied in the analytical models, the multicollinearity condition number was 70.59. Generally, the GeoDa 9.3 program used in this study determines that a multicollinearity condition number $\geq 30$ is an indication of a multicollinearity problem [38]. Accordingly, residential density $\left(X_{1}\right)$, commercial density $\left(X_{2}\right)$, entropy index $\left(X_{5}\right)$, industrial mixture index $\left(X_{9}\right)$, global integration $\left(X_{11}\right)$ and local integration $\left(X_{12}\right)$ were excluded, as these showed high correlation within independent variables. Subsequently, the multicollinearity condition number of the analytical model with the entry of the final selection of variables was calculated to be 14.34; this confirmed that the prerequisite for the regression model was satisfied.

Figure 4 shows the synthesized flowchart of the analysis methodology based on literature review to test hypotheses described above.

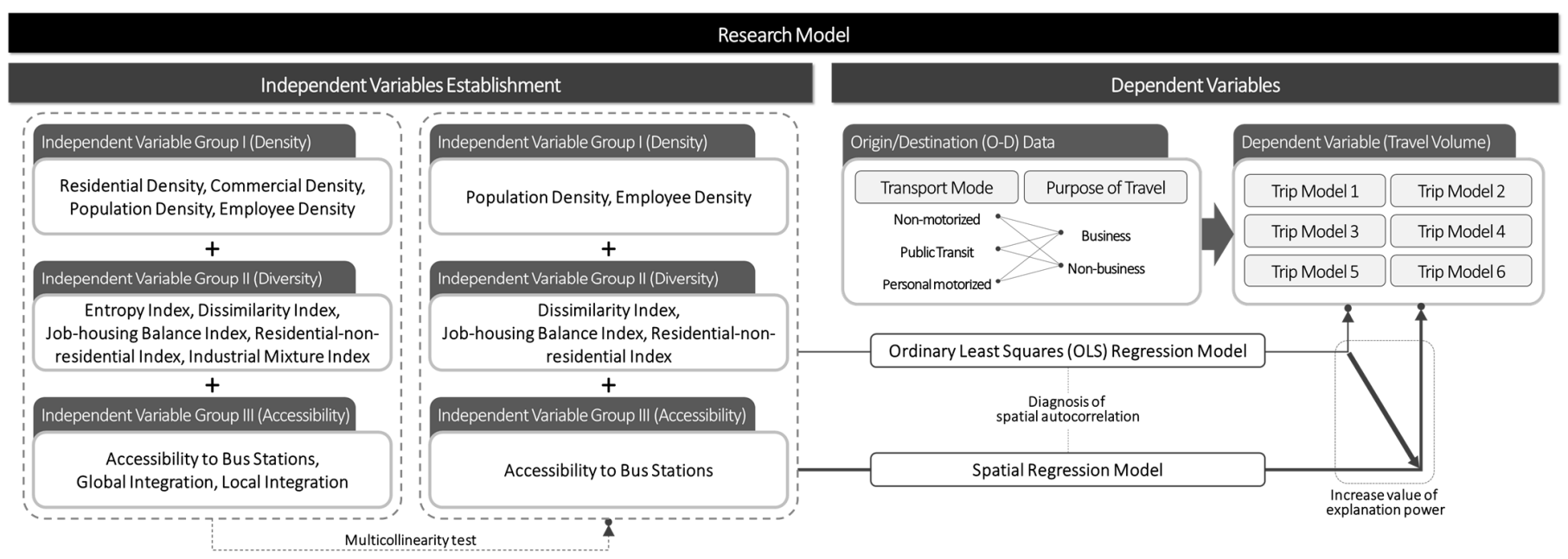

Figure 4. A Synthesized Flowchart of the Analysis Methodology of this Study.

\section{Results}

\subsection{Comparison Between OLS and SR Models}

To determine the statistical fitness of the OLS model (a traditional regression model) and SR model, non-normality and heteroscedasticity of the error term were diagnosed. Analyses of all trip models showed statistical significance in the Jarque-Bera and BreuschPagan statistics, which confirmed non-normality and heteroscedasticity of the error term in the OLS model. Based on these findings, it was determined that the SR model is the most suitable analytical model for resolving this problem [58].

Next, the explanatory power was compared between the OLS and SR models. Since absolute comparison between the two models by $\mathrm{R}^{2}$ values was not possible, relative comparison was made using log likelihood (LL), Akaike information criterion (AIC) and Schwarz criterion (SC) [59]. As shown in Tables 5-7, LL of all trip models was higher in the SR model than in the OLS model, while AIC and SC were lower in the SR model than in the OLS model. Since the explanatory power of the SR model was improved over the OLS model for all trip models, it could be concluded that the SR model performed better than the OLS model in analyzing the data. 
Table 5. Results of ordinary least squares (OLS) and spatial regression (SR) analyses (Models 1 and 2).

\begin{tabular}{|c|c|c|c|c|c|c|c|c|c|c|c|c|}
\hline \multirow{3}{*}{ Division } & \multicolumn{6}{|c|}{ Model 1} & \multicolumn{6}{|c|}{ Model 2} \\
\hline & \multicolumn{2}{|l|}{ OLS } & \multicolumn{2}{|l|}{ SLM } & \multicolumn{2}{|l|}{ SEM } & \multicolumn{2}{|l|}{ OLS } & \multicolumn{2}{|l|}{ SLM } & \multicolumn{2}{|l|}{ SEM } \\
\hline & B (Sig.) & $\mathbf{t}$ & B (Sig.) & $\mathbf{t}$ & B (Sig.) & $\mathbf{t}$ & B (Sig.) & $\mathbf{t}$ & B (Sig.) & $\mathbf{t}$ & B (Sig.) & $\mathbf{t}$ \\
\hline$X_{3}$ & $0.008(0.000 * *)$ & 15.224 & $0.007(0.000 * *)$ & 14.056 & $0.007\left(0.000^{* *}\right)$ & 14.638 & $0.005(0.000 * *)$ & 14.324 & $0.005(0.000 * *)$ & 13.263 & $0.005\left(0.000^{* *}\right)$ & 13.861 \\
\hline$X_{4}$ & $0.001\left(0.000^{* *}\right)$ & 3.564 & $0.001(0.000 * *)$ & 3.595 & $0.001\left(0.001^{* *}\right)$ & 3.201 & $0.001\left(0.004^{* *}\right)$ & 2.925 & $0.001(0.003 * *)$ & 2.954 & $0.001\left(0.010^{* *}\right)$ & 2.589 \\
\hline$X_{6}$ & $-35.139(0.550)$ & -0.598 & $8.875(0.878)$ & 0.153 & $-7.707(0.901)$ & -0.125 & $-35.818(0.383)$ & -0.873 & $-8.609(0.832)$ & -0.213 & $-25.286(0.557)$ & -0.587 \\
\hline$X_{7}$ & $-8.532(0.713)$ & -0.368 & $-11.160(0.620)$ & -0.496 & $-16.139(0.490)$ & -0.690 & $-3.893(0.810)$ & -0.241 & $-5.176(0.742)$ & -0.329 & $-8.717(0.593)$ & -0.535 \\
\hline$X_{8}$ & $33.657(0.143)$ & 1.469 & $22.059(0.323)$ & 0.988 & $22.596(0.329)$ & 0.976 & $16.717(0.296)$ & 1.046 & $9.442(0.545)$ & 0.605 & $10.653(0.509)$ & 0.660 \\
\hline$X_{10}$ & $1594.840(0.545)$ & 0.607 & $2474.757(0.333)$ & 0.969 & $3521.384(0.183)$ & 1.332 & $802.976(0.662)$ & 0.438 & $1363.534(0.445)$ & 0.764 & $2005.877(0.277)$ & 1.088 \\
\hline Constant & \multirow{2}{*}{\multicolumn{2}{|c|}{$43.11 \%$}} & $-33.547(0.136)$ & -1.491 & $11.583(0.575)$ & 0.560 & $13.649(0.668)$ & 0.958 & $-13.573(0.386)$ & -0.866 & $15.895(0.270)$ & 1.103 \\
\hline adjusted $R^{2}$ & & & $45.44 \%$ & & \multicolumn{2}{|l|}{$46.04 \%$} & \multicolumn{2}{|l|}{$39.80 \%$} & $42.07 \%$ & & \multicolumn{2}{|l|}{$42.90 \%$} \\
\hline Rho & & & $0.219\left(0.000^{* *}\right)$ & 3.831 & & & & & $0.213\left(0.000^{* *}\right)$ & 3.622 & & \\
\hline Lambda & & & & & $0.283(0.000 * *)$ & 4.033 & & & & & $0.280\left(0.000^{* *}\right)$ & 3.995 \\
\hline Jarque-Bera & $(0.000 * *)$ & 199.333 & & & & & $\left(0.000^{* *}\right)$ & 138.064 & & & & \\
\hline Breusch-Pagan & $\left(0.000^{* *}\right)$ & 30.912 & & & & & $\left(0.007^{* *}\right)$ & 17.574 & & & & \\
\hline Log Likelihood & & -2479.700 & & -2472.710 & & -2471.699 & & -2327.020 & & -2320.670 & & -2318.991 \\
\hline AIC & & 4973.400 & & 4961.430 & & 4957.400 & & 4668.040 & & 4657.340 & & 4651.980 \\
\hline SC & & 5001.750 & & 4993.830 & & 4985.750 & & 4696.390 & & 4689.730 & & 4680.330 \\
\hline LM-lag & $(0.000 * *)$ & 15.344 & & & & & $(0.000 * *)$ & 14.161 & & & & \\
\hline Robust LM-lag & $(0.436)$ & 0.608 & & & & & $(0.736)$ & 0.114 & & & & \\
\hline LM-error & $(0.000 * *)$ & 19.173 & & & & & $(0.000 * *)$ & 19.624 & & & & \\
\hline
\end{tabular}

Table 6. Results of ordinary least squares (OLS) and spatial regression (SR) analyses (Models 3 and 4).

\begin{tabular}{|c|c|c|c|c|c|c|c|c|c|c|c|c|}
\hline \multirow{3}{*}{ Division } & \multicolumn{6}{|c|}{ Model 3} & \multicolumn{6}{|c|}{ Model 4} \\
\hline & \multicolumn{2}{|l|}{ OLS } & \multicolumn{2}{|l|}{ SLM } & \multicolumn{2}{|l|}{ SEM } & \multicolumn{2}{|l|}{ OLS } & \multicolumn{2}{|l|}{ SLM } & \multicolumn{2}{|l|}{ SEM } \\
\hline & B (Sig.) & $t$ & B (Sig.) & $\mathrm{t}$ & B (Sig.) & $\mathrm{t}$ & B (Sig.) & $\mathrm{t}$ & B (Sig.) & $\mathrm{t}$ & B (Sig.) & $t$ \\
\hline$X_{3}$ & $-0.001(0.313)$ & -1.010 & $0.000(0.862)$ & -0.174 & $-0.001(0.479)$ & -0.707 & $-0.002(0.110)$ & -1.603 & $-0.001(0.463)$ & -0.735 & $-0.001(0.184)$ & -1.329 \\
\hline$X_{4}$ & $0.016\left(0.000^{* *}\right)$ & 22.086 & $0.015\left(0.000^{* *}\right)$ & 20.678 & $0.015\left(0.000^{* *}\right)$ & 20.681 & $0.014\left(0.000^{* *}\right)$ & 24.163 & $0.013\left(0.000^{* *}\right)$ & 22.658 & $0.013\left(0.000^{* *}\right)$ & 23.135 \\
\hline$X_{6}$ & $507.819\left(0.000^{* *}\right)$ & 3.641 & $337.136\left(0.013^{* *}\right)$ & 2.491 & $470.698\left(0.001^{* *}\right)$ & 3.231 & $373.975\left(0.001^{* *}\right)$ & 3.362 & $222.809\left(0.039^{*}\right)$ & 2.068 & $338.874\left(0.003^{* *}\right)$ & 2.951 \\
\hline$X_{7}$ & $-12.766(0.816)$ & -0.232 & $-70.019(0.188)$ & -1.315 & $-16.981(0.603)$ & -0.304 & $-22.819(0.603)$ & -0.521 & $-70.804\left(0.095^{\dagger}\right)$ & -1.667 & $-24.449(0.582)$ & -0.551 \\
\hline$X_{8}$ & $-190.229\left(0.003^{* *}\right)$ & -3.499 & $-131.026\left(0.013^{* *}\right)$ & -2.487 & $-180.108\left(0.001^{* *}\right)$ & -3.262 & $-132.989(0.002 * *)$ & -3.068 & $-83.078(0.048 *)$ & -1.980 & $-124.291\left(0.005^{* *}\right)$ & -2.833 \\
\hline$X_{10}$ & $45,405.700(0.000 * *)$ & 7.277 & $44,638.350\left(0.000^{* *}\right)$ & 7.496 & $47,296.170\left(0.000^{* *}\right)$ & 7.484 & $32,751.000(0.000 * *)$ & 6.582 & $32,021.850(0.000 * *)$ & 6.755 & $33,436.680(0.000 * *)$ & 6.649 \\
\hline Constant & $16.758(0.730)$ & 0.346 & $-39.699(0.398)$ & -0.844 & $17.574(0.721)$ & 0.357 & $22.293(0.564)$ & 0.577 & $-20.002(0.593)$ & -0.535 & $23.893(0.541)$ & 0.611 \\
\hline adjusted $R^{2}$ & $69.90 \%$ & & $72.26 \%$ & & $70.51 \%$ & & $72.13 \%$ & & $74.37 \%$ & & $72.39 \%$ & \\
\hline $\begin{array}{l}\text { Lambda } \\
\text { Jarque-Bera }\end{array}$ & $(0.000 * *)$ & 1802.842 & & & $0.204(0.005 * *)$ & 2.781 & $(0.000 * *)$ & 1636.561 & & & $0.146\left(0.053^{\dagger}\right)$ & 1.932 \\
\hline
\end{tabular}


Table 6. Cont

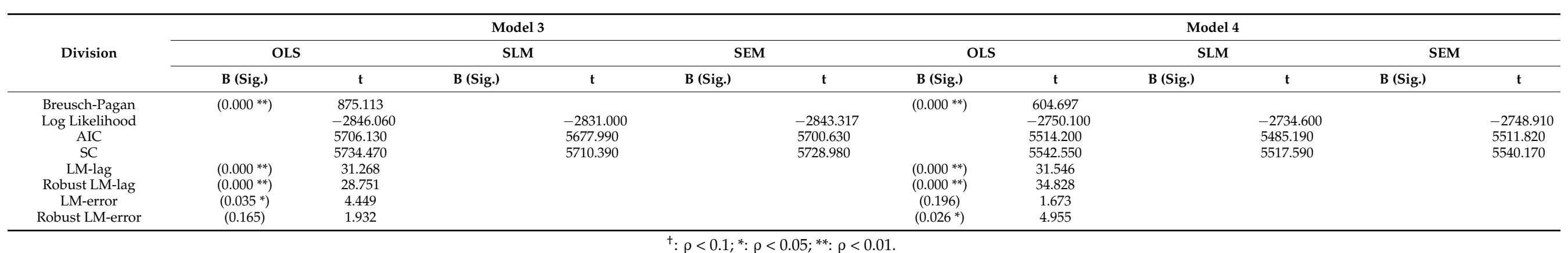

Table 7. Results of ordinary least squares (OLS) and spatial regression (SR) analyses (Models 5 and 6).

\begin{tabular}{|c|c|c|c|c|c|c|c|c|c|c|c|c|}
\hline \multirow{3}{*}{ Division } & \multicolumn{6}{|c|}{ Model 5} & \multicolumn{6}{|c|}{ Model 6} \\
\hline & \multicolumn{2}{|l|}{ OLS } & \multicolumn{2}{|l|}{ SLM } & \multicolumn{2}{|l|}{ SEM } & \multicolumn{2}{|l|}{ OLS } & \multicolumn{2}{|l|}{ SLM } & \multicolumn{2}{|l|}{ SEM } \\
\hline & B (Sig.) & $\mathrm{t}$ & B (Sig.) & $\mathrm{t}$ & B (Sig.) & $t$ & B (Sig.) & $t$ & B (Sig.) & $t$ & B (Sig.) & $t$ \\
\hline$X_{3}$ & $0.004(0.000 * *)$ & 6.119 & $0.004(0.000 * *)$ & 6.272 & $0.004(0.000 * *)$ & 6.120 & $0.002(0.000 * *)$ & 4.612 & $0.002(0.000 * *)$ & 4.802 & $0.002(0.000 * *)$ & 4.769 \\
\hline $\begin{array}{l}X_{4} \\
X_{6}\end{array}$ & $12.389(0.859)$ & 0.178 & $-9.569(0.888)$ & -0.141 & $13.032(0.851)$ & 0.188 & $46.552(0.429)$ & 0.791 & $19.374(0.736)$ & 0.337 & $47.525(0.408)$ & 0.827 \\
\hline$X_{7}$ & $91.635(0.001 * *)$ & 3.337 & $57.965(0.034 *)$ & 2.123 & $89.972(0.001 * *)$ & 3.293 & $48.531\left(0.037^{*}\right)$ & 2.094 & $23.564(0.308)$ & 1.019 & $52.206(0.022 *)$ & 2.293 \\
\hline$X_{8}$ & $-41.051(0.132)$ & -1.511 & $-25.650(0.333)$ & -0.968 & $-40.697(0.132)$ & -1.506 & $-22.518(0.327)$ & -0.982 & $-10.024(0.656)$ & -0.445 & $-23.363(0.300)$ & -1.037 \\
\hline$X_{10}$ & $9937.405\left(0.002^{* *}\right)$ & 3.187 & $10,543.930\left(0.000^{* *}\right)$ & 3.492 & $10,046.920\left(0.001^{* *}\right)$ & 3.239 & $8161.118(0.002 * *)$ & 3.100 & $8467.851(0.001 * *)$ & 3.306 & $7981.830(0.002 * *)$ & 3.087 \\
\hline Constant & $-33.217(0.171)$ & -1.372 & $-56.680\left(0.019^{*}\right)$ & -2.344 & $-32.650(0.175)$ & -1.356 & $-33.134(0.106)$ & -1.621 & $-47.891\left(0.019^{*}\right)$ & -2.348 & $-34.963\left(0.082^{+}\right)$ & -1.741 \\
\hline adjusted $R^{2}$ & $74.44 \%$ & & $75.64 \%$ & & $74.44 \%$ & & $76.16 \%$ & & $77.05 \%$ & & $76.18 \%$ & \\
\hline $\begin{array}{l}\text { Lambda } \\
\text { Jarque-Bera }\end{array}$ & $(0.000 * *)$ & 2060.955 & & & $0.017(0.835)$ & 0.209 & $(0.000 * *)$ & 2876.487 & & & $-0.048(0.557)$ & -0.587 \\
\hline Breusch-Pagan & $(0.000 * *)$ & 474.745 & & & & & $(0.000 * *)$ & 719.701 & & & & \\
\hline Log Likelihood & & -2552.020 & & -2542.930 & & -2552.009 & & -2480.140 & & -2472.870 & & -2480.016 \\
\hline AIC & & 5118.050 & & 5101.860 & & 5118.020 & & 4974.290 & & 4961.740 & & 4974.030 \\
\hline SC & & 5146.400 & & 5134.260 & & 5146.370 & & 5002.640 & & 4994.140 & & 5002.380 \\
\hline LM-lag & $(0.000 * *)$ & 19.929 & & 10107.200 & & $1+0.0 \%$ & $(0.000 * *)$ & 15.884 & & (7) & & 0002.000 \\
\hline Robust LM-lag & $\left(0.000^{* *}\right)$ & 26.616 & & & & & $\left(0.000 * 0^{*}\right)$ & 23.960 & & & & \\
\hline LM-error & $(0.882)$ & 0.022 & & & & & $(0.665)$ & 0.187 & & & & \\
\hline Robust LM-error & $(0.010 *)$ & 6.710 & & & & & $\left(0.004^{* *}\right)$ & 8.263 & & & & \\
\hline
\end{tabular}


Moreover, Models 1 and 2 (i.e., trip models using a non-motorized mode) showed improved explanatory power in the spatial error model (SEM), while the other four models (i.e., trip models using a motorized mode) showed improved explanatory power in the spatial lag model (SLM). The results indicated that the SR model is more suitable for the analysis than the OLS model; the SEM is more suitable for trip models using non-motorized modes, whereas the SLM is more suitable for trip models using motorized modes. Based on these findings, it was determined that travel that takes place within a small spatial range using a non-motorized mode, such as walking or bicycling, is affected more by land-use characteristics than travel using a non-motorized mode in neighboring areas and that travel using a motorized mode has a lag according to the volume of travel using a motorized mode in neighboring areas.

\subsection{SR Model Results}

The SR analysis found that population density in both Models $1(t=14.638, \rho=0.000)$ and Model $2(t=13.861, \rho=0.000)$ and employee density in both Models $1(t=3.201$, $\rho=0.001)$ and $2(t=2.589, \rho=0.010)$ were significant variables (see Table 5). Specifically, for travel using non-motorized modes, business travel increased with unit increase in population and employee density. Non-business travel also increased with unit increase in population and employee density; however, its increase was less than that of business travel. All other diversity and accessibility-related variables were found to be insignificant variables, which contradicts the results of previous studies $[1,4,13,17]$.

In Models 3 and 4, both were found to be significantly affected by density, diversity and accessibility-related variables (see Table 6). Specifically, both business and non-business travel using public transit modes increased with an increase in employee density $(t=20.678$, $\rho=0.000$ in Model 3, $t=22.658, \rho=0.000$ in Model 4), dissimilarity between neighboring land-use ( $\mathrm{t}=2.491, \rho=0.013$ in Model 3, $\mathrm{t}=2.068, \rho=0.039$ in Model 4) and bus accessibility $(\mathrm{t}=7.496, \rho=0.000$ in Model 3, $\mathrm{t}=6.755, \rho=0.000$ in Model 4). However, all travel using public transit modes decreased as the residential to non-residential ratio within the administrative neighborhood became more balanced $(t=-2.487, \rho=0.013$ in Model 3, $\mathrm{t}=-1.980, \rho=0.048$ in Model 4). Moreover, job-housing proximity $(\mathrm{t}=-1.667, \rho=0.095$ in Model 4) had a significant effect only on non-business travel using public transit; a negative (-) relationship between the interactions was found. Meanwhile, land-use characteristics had a stronger effect on business travel between these two trip models and the results also showed that diversity and accessibility-related variables had a greater effect on the change in travel volume than did density-related variables.

In Models 5 and 6, both were found to be significantly affected by density, diversity and accessibility-related variables (see Table 7). Specifically, both business and non-business travel using personal motorized modes increased with increases in population density $(t=6.272, \rho=0.000$ in Model 5, $t=4.802, \rho=0.000$ in Model 6), employee density $(t=24.963$, $\rho=0.000$ in Model 5, $t=26.997, \rho=0.000$ in Model 6) and bus accessibility $(t=3.492$, $\rho=0.000$ in Model 5, $t=3.306, \rho=0.001$ in Model 6). Moreover, job-housing proximity was found to be a significant variable for both trip models in the OLS analysis; however, it had a significant effect only on business travel $(t=2.123, \rho=0.034$ in Model 5) in the SLM. With respect to changes in travel according to unit change in land-use characteristics, the results were similar to those of Models 3 and 4 described above, with business travel showing a greater margin of change than non-business travel and diversity and accessibilityrelated variables having a greater effect on the change in travel volume than densityrelated variables.

Three key findings can be derived from the results of this study (see Table 8). First, among density-related variables, employee density increased the use of all transport modes, with an especially large increase in the use of public transit only on business travel $(B=0.015)$. Although employee density facilitating the use of personal motorized means of transport contradicted the results of previous studies, the fact that it facilitated the use of public transit $(\mathrm{B}=0.015$ in Model 3, $\mathrm{B}=0.013$ in Model 4) more than the use of personal 
motorized modes $(B=0.009$ in Model $5, B=0.008$ in Model 6$)$ was in the same context as the results of previous studies $[1,11,17,22]$. Meanwhile, both population density and employee density facilitated the use of non-motorized and personal motorized modes, with the use of non-motorized modes being facilitated more by population density $(B=0.007$ in Model $1, \mathrm{~B}=0.005$ in Model 2) and the use of personal motorized modes being facilitated more by employee density $(B=0.004$ in Model 5, $B=0.002$ in Model 6). Based on these results, it was determined that to promote walking, it is more effective to increase population density than employee density.

Table 8. Unstandardized coefficients of spatial regression (SR) analyses (Models 1 6).

\begin{tabular}{|c|c|c|c|c|c|c|}
\hline Independent Variable & Model 1 & Model 2 & Model 3 & Model 4 & Model 5 & Model 6 \\
\hline Population density $\left(X_{3}\right)$ & +0.007 & +0.005 & $\mathrm{n} / \mathrm{a}$ & $\mathrm{n} / \mathrm{a}$ & +0.004 & +0.002 \\
\hline Employees density $\left(X_{4}\right)$ & +0.001 & +0.001 & +0.015 & +0.013 & +0.009 & +0.008 \\
\hline Dissimilarity index $\left(X_{6}\right)$ & $\mathrm{n} / \mathrm{a}$ & $\mathrm{n} / \mathrm{a}$ & +337.136 & +222.809 & $\mathrm{n} / \mathrm{a}$ & $\mathrm{n} / \mathrm{a}$ \\
\hline Job-housing index $\left(X_{7}\right)$ & $\mathrm{n} / \mathrm{a}$ & $\mathrm{n} / \mathrm{a}$ & $\mathrm{n} / \mathrm{a}$ & -70.804 & 57.965 & $\mathrm{n} / \mathrm{a}$ \\
\hline Residential-non-residential index $\left(X_{8}\right)$ & $\mathrm{n} / \mathrm{a}$ & $\mathrm{n} / \mathrm{a}$ & -131.026 & -83.078 & $\mathrm{n} / \mathrm{a}$ & $\mathrm{n} / \mathrm{a}$ \\
\hline Bus accessibility $\left(X_{10}\right)$ & $\mathrm{n} / \mathrm{a}$ & $\mathrm{n} / \mathrm{a}$ & $+44,638.350$ & $+32,021.850$ & $+10,543.930$ & +8467.851 \\
\hline
\end{tabular}

Second, diversity-related variables only affected travel using motorized modes, such as public transit and personal motorized means, and, showed a significant effect mostly on the use of public transit. Specifically, it was effective in enhancing the use of public transit when the land-use between neighboring lots was diverse $(B=337.136$ in Model 3, $B=222.809$ in Model 4); the results confirmed that planning with a similar scale of residential and non-residential buildings could be a factor that contributes to decreases in the use of public transit $(\mathrm{B}=-131.026$ in Model 3, $\mathrm{B}=-83.078$ in Model 4). Meanwhile, travel using personal motorized modes was affected by job-housing proximity only for business travel ( $\mathrm{B}=57.965$ in Model 5). Moreover, favorable job-housing proximity led to increased business travel using personal motorized modes $(B=57.965$ in Model 5) but decreased non-business travel using public transit $(B=-70.804$ in Model 4). These findings supported the third hypothesis of this study.

Third, bus accessibility, which is one of the accessibility-related variables, was impactful only on travel using motorized modes. Higher bus accessibility led to higher use of both public transit ( $\mathrm{B}=44,638.350$ in Model 3, $\mathrm{B}=32,021.850$ in Model 4) and personal motorized means of transport $(B=10,543.930$ in Model 5, $B=8467.851$ in Model 6), with about four times greater increase measured in the former.

Additionally, two main findings through comparison of methodology for regression analysis, OLS and SR, can be derived from the results of this study. First, travel using non-motorized modes showed a greater spatial influence on the dependent variable than travel using motorized modes. In Models 1 and 2, the spatial influences on the dependent variable were $28.3 \%$ and $28.0 \%$, respectively, which were higher than those of other trip models (See Table 5). In Models 5 and 6, that is, the trip models using personal motorized modes, the spatial influences on the dependent variable were very low at $16.8 \%$ and $14.7 \%$, respectively (See Table 7). This could also be confirmed by comparing the explanatory power between the OLS and SR analysis results for each trip model. Travel that was less affected by spatial influence showed a smaller increase in the explanatory power of the SR model compared to that of the OLS model.

Second, the OLS and SR models demonstrated that non-business travel using motorized modes showed a difference in whether job-housing proximity acts as a significant variable. This indicates that although the estimates obtained by the OLS analysis may assure unbiased outputs, inaccurate assumptions may have been reached in the significance test due to inefficiency; if so, this presents the risk of reaching a false conclusion, which has policy implications. This highlights the importance of selecting the most suitable analytical method by considering the characteristics of the variables. 


\subsection{Hypothesis Test}

The results of testing the hypotheses of this study based on the analysis results are as follows. First, the dependent variable (i.e., travel volume) showed spatial autocorrelation and in particular, travel using non-motorized modes exhibited the greatest spatial influence. When the SR analysis was performed accordingly, each trip model showed higher explanatory power compared to that of the OLS analytical models, with travel using non-motorized modes showing the highest margin of increase in explanatory power. Such findings demonstrated that when travel volume was used as the dependent variable, better results could be obtained by using the SR rather than the OLs analysis; therefore, the SR analysis is a more suitable method, especially for analyzing pedestrian traffic volume.

Second, the variables associated with land-use characteristics that affect transport mode choices according to the purpose of travel showed greater differences in travel using motorized modes than in travel using non-motorized modes. The variable that showed a difference was job-housing proximity and unlike the results reported in existing studies, higher job-housing proximity resulted in decreased non-business travel using public transit mode and increased business travel using personal motorized mode. However, the effects of land-use characteristics on travel were unexpectedly stronger in business trip models.

Third, an increase in land-use diversity did not always facilitate the use of nonmotorized or public transit modes; in contrast, such an increase did not always cause a reduction in the use of personal motorized modes. In this study, the effects of diversity and accessibility of land-use on travel were significant only in travel using motorized modes and not in travel using non-motorized modes. Moreover, density and accessibility were variables that increased not only non-motorized and public transit modes but also the use of personal motorized modes. Our findings demonstrate that the results reported in previous studies cannot be derived in all urban areas.

\section{Discussion and Implications}

This study investigated the effects of land-use characteristics on the transport mode choices of people according to their purpose of travel in Seoul, which is a densely developed city and the capital of South Korea. Land-use characteristics of 424 administrative neighborhoods in Seoul were divided into density, diversity and accessibility-related variables and the relationships between these variables and the travel volume entering these administrative neighborhoods by the purpose of travel and transport mode were analyzed using regression models. Prior to the analysis, spatial autocorrelation of the dependent variable was diagnosed; the SR model showed superior explanatory power compared to the OLS model, which indicated that the SR model was a more suitable regression analysis model for this study.

The following implications were derived based on the findings of this study. First, the effects of land-use characteristics on travel showed more distinct differences based on transport mode than on purpose of travel. Comparison of variables associated with land-use characteristics showed that differences of increasing or decreasing travel in such variables were prominent according to the transport mode. On the other hand, for travel using the same transport mode, there were only some very small differences of values according to the purpose of travel. These findings could be interpreted as meaning that the transport mode choice is more affected by land-use characteristics than by the purpose of travel. Moreover, comparison in travel volume according to each variable associated with land-use characteristics showed that the change in volume in business travel was higher than that in non-business travel, indicating a greater effect of land-use characteristics.

Secondly, diversity-related variables did not have a consistent effect on increasing or decreasing travel and did not always increase the use of public transit. This may be because Seoul is a city where land-use was already mixed and compacted, thus increasing the diversity of land-use would not clearly demonstrate decreased travel distance or increased travel convenience. However, there are limitations in reaching conclusions based on the physical conditions of the city without considering the personal characteristics 
of travelers. Therefore, additional studies are needed for multi-dimensional analysis on the factors that affect travel by considering land-use characteristics together with the socioeconomic situation of travelers and other factors associated with convenience, autonomy and travel efficiency.

In addition, when conducting a study on travel volume, the spatial influence on travel should be considered to select a suitable study methodology. Generally, hierarchies and traits of a city are formed based on function, which causes similar buildings to be densely located within a specific area. Typical examples include apartment complexes and commercial or industrial zones populated by buildings for a specific use. Considering that the facility of need for the traveler is located at the destination, areas that are densely populated by buildings for a specific use would attract travel for a specific purpose, which suggests that areas with inflow of specific travel are highly likely to be densely populated by buildings. Therefore, when administrative districts are used as the unit space for analysis (as in this study), administrative districts that are spatially close demonstrate high correlation due to sharing similar urban characteristics, and, thus, an analytical method that can control for spatial autocorrelation is needed. Many previous studies used OLS analysis to study causal relationships between independent and dependent variables [29,31-34]. This study revealed that in situations with spatial correlation, such as travel analysis, using OLS analysis will produce different results or explanatory power of the model than SR analysis. In particular, travel using non-motorized modes, such as walking, was found to be significantly affected by surrounding land-use characteristics; thus, SR analysis should be used together with an analytical method that can control spatial correlation to ensure accurate results.

Finally, the results showed that different SR models (SEM or SLM) were more suitable for different trip models. It is inferred that this may be attributed to differences in the size of the space and the mobility of each transport mode. Travel using non-motorized modes tended to have shorter average distances traveled and narrower travel boundaries than travel using motorized modes. In this study, the average size of administrative neighborhoods (i.e., the unit space analyzed) was approximately $1.42 \mathrm{~km}^{2}$ and the average built-up area was $0.84 \mathrm{~km}^{2}$. On the other hand, when the boundary of walking is calculated as having a radius of $400 \mathrm{~m}$ to represent a 5-min walking distance, the origin and destination of travel may be in the same administrative neighborhood when traveling $0.5 \mathrm{~km}^{2}$ by a non-motorized mode; as a result, the frequency of such incoming travel from another administrative neighborhood is highly likely to be lower than that of travel by motorized modes. Therefore, administrative neighborhoods could be viewed as a unit space that is more suitable for analyzing travel using motorized modes than travel using non-motorized modes. The fact that the explanatory power was higher for the trip models using motorized modes than for those using non-motorized modes can be understood in the same context. Travel using non-motorized modes is expected to show increased explanatory power for the model when analyzing unit spaces that are smaller in size than administrative neighborhoods. It is believed that this aspect should be investigated in future studies.

This study has the following historic research significance and limitations. First, this study is significant in that it highlights the limitations of OLS analysis, which has previously been widely used in studies on travel volume; this study proposes SR analysis as an improved alternative. Moreover, another significance of this study is that a multidimensional comparative analysis was conducted on the effects of land-use characteristics on travel by considering all types of purpose of travel and transport mode, rather than solely business travel. By reflecting the relationship between the characteristics of land-use and traffic through the analysis results, a regional transportation plan and a land-use plan are established, thereby enabling sustainable transport demand management and urban development within the city. In addition, when promoting a new city development project or a large-scale development project, sustainable walkable communities can be formed by creating a community within the pedestrian zone by increasing the residential density and commercial density to promote pedestrian travel. In this study we were unable to 
control for socioeconomic characteristics (which represent the personal characteristics of travelers), due to data acquisition issues; this could be viewed as a limitation of this study. The findings showed that increased bus accessibility caused an increase in travel using personal motorized modes, which indicated that even when public transit accessibility was improved by increased bus accessibility, people who travel using personal motorized modes do not easily change their transport preference. Considering that areas with high bus accessibility typically have good traffic networks for regular vehicles [60], the reasons for such results could be that the benefits of travel convenience, autonomous mobility and time efficiency that are offered by personal motorized modes are greater than those offered by other transport modes; as a result, people may choose personal motorized modes even if they have to pay a higher cost than to use other transport modes. In other words, it seems likely that the choice of personal motorized mode may be more affected by intrinsic factors, such as personal socioeconomic level, than by extrinsic factors, such as land-use characteristics and physical conditions of the city. Models 5 and 6 (i.e., trip models using personal motorized modes) showed less spatial influence than other models, which could be understood in the same context [19]. Therefore, if socioeconomic characteristics are incorporated into future research as independent variables, results with higher explanatory power may be obtained on transport mode choices. Accordingly, future studies are needed.

Moreover, there is a need to use the global positioning system (GPS) linear data (i.e., route data) to analyze travel patterns of motorized means and pedestrians in the city. O-D data used in this study consists of point data as the starting point and the destination point of travel, for that reason, specific route information is not included in O-D data. However, through linear route data extracted from GPS data, the effect of micro-scale environmental conditions (i.e., mean block size within a walkable zone, distance to the specific program of a building and total length of travel) on travel can be derived as suggested by Lee and Moudon (2006) [24]. In addition, GPS tracking data can respond to on-demand traffic service within meso-scale area, such as a district or the specific zones and establish the hierarchy of urban spatial structure with the trip network [61,62].

Finally, there is a need to review sophisticated analytical models based on the SR analysis results found in this study. Because transport mode choices are affected by intrinsic factors, such as the aforementioned socioeconomic characteristics, additional considerations are needed. It is expected that studies on travel will continue to incorporate sophisticated models based on the findings of this study.

Author Contributions: Conceptualization, B.M. and G.L.; Data curation, B.M.; Formal analysis, B.M.; Investigation, B.M.; Methodology, B.M.; Resources, B.M.; Software, B.M.; Supervision, S.K.; Validation, B.M. and G.L.; Visualization, B.M.; Writing-original draft, B.M.; Writing-review \& editing, B.M., G.L. and S.K. All authors have read and agreed to the published version of the manuscript.

Funding: This research received no external funding.

Data Availability Statement: Datasets used in this study are publicly available. The number of workers by industry and resident registration population data are provided by Statistics Korea (https://kosis.kr). The areal data of bulidings and lands, list of bus routes, and road networks are provided by Seoul Metropolitan Government (http://data.seoul.go.kr). O-D data from the household travel are available from Korea Transport Database (https: / /www.ktdb.go.kr).

Acknowledgments: This research was supported by a grant(21TSRD-B151228-03) from Urban Declining Area Regenerative Capacity-Enhancing Technology Research Program funded by Ministry of Land, Infrastructure and Transport of Korean government.

Conflicts of Interest: The author declares no conflict of interest.

\section{References}

1. Cervero, R. Land-Use Mixing and Suburban Mobility. Transportation 1988, 42, 429-446.

2. Ewing, R.; Meakins, G.; Hamidi, S.; Nelson, A.C. Relationship between urban sprawl and physical activity, obesity, and morbidity-Update and refinement. Health Place 2014, 26, 118-126. [CrossRef] [PubMed] 
3. Song, Y.; Knapp, G.-J. Measuring Urban Form. Is Portland Winning the War on Sprawl. J. Am. Plan. Assoc. 2004, 70, $210-225$. [CrossRef]

4. Cervero, R. Transport and Land Use. Aust. Plan. 2001, 38, 29-37. [CrossRef]

5. Cervero, R. The Built Environment and Travel: Evidence from the United States. Eur. J. Trans. Infrastruct. Res. $2003,3,119-137$.

6. Cervero, R.; Kang, C.D. Bus rapid transit impacts on land uses and land values in Seoul, Korea. Transp. Policy 2011, 18, 102-116. [CrossRef]

7. Downs, A. Smart Growth: Why We Discuss It More than We Do It. J. Am. Plan. Assoc. 2005, 71, 367-378. [CrossRef]

8. Kii, M.; Doi, K. Multiagent Land-Use and Transport Model for the Policy Evaluation of a Compact City. Environ. Plan. B Plan. Des. 2005, 32, 485-504. [CrossRef]

9. Berawi, M.A.; Saroji, G.; Iskandar, F.A.; Ibrahim, B.E.; Miraj, P.; Sari, M. Optimizing Land Use Allocation of Transit-Oriented Development (TOD) to Generate Maximum Ridership. Sustainability 2020, 12, 3798. [CrossRef]

10. Jacobs, J. The Death and Life of Great American Cities; Vintage Books: New York, NY, USA, 1992.

11. Cervero, R. Jobs-Housing Balancing and Regional Mobility. Am. Plan. Assoc. 1989, 55, 136-150. [CrossRef]

12. Cervero, R. Built environments and mode choice: Toward a normative framework. Trans. Res. Part. D Trans. Environ. 2002, 7 , 265-284. [CrossRef]

13. Frank, L.D.; Pivo, G. Impacts of mixed use and density on utilization of three modes of travel: Single occupant vehi- cle, transit, and walking. Trans. Res. Rec. J. Trans. Res. Board 1994, 1466, 44-52. [CrossRef]

14. Tsai, Y.H. Quantifying Urban Form: Compactness versus 'Sprawl'. Urban Stud. 2005, 42, 141-161. [CrossRef]

15. Ewing, R.; Cervero, R. Travel and the Built Environment-A Synthesis. Trans. Res. Rec. 2001, 1780, 87-114. [CrossRef]

16. Ewing, R.; Cervero, R. Travel and the Built Environment-A Meta Analysis. J. Am. Plan. Assoc. 2010, 76, 265-294. [CrossRef]

17. Cervero, R.; Kockelman, K. Travel demand and the 3Ds: Density, diversity, and design. Trans. Res. Part D Trans. Environ. 1997, 2, 199-219. [CrossRef]

18. Gim, T.H.T. Full Random Coefficients Multilevel Modeling of the Relationship between Land Use and Trip Time on Weekdays and Weekends. Sustainability 2017, 9, 1824. [CrossRef]

19. Handy, S. Methodologies for exploring the link between urban form and travel behavior. Trans. Res. Part D Trans. Environ. 1996, 1, 151-165. [CrossRef]

20. Kato, H.; Igo, T.; Furuhashi, M. How Much Does Land Use Mix Impact on Travel Frequency. J. East. Asia Soc. Trans. Stud. 2013, 10, 454-467. [CrossRef]

21. Cervero, R.; Radisch, C. Travel choices in pedestrian versus automobile oriented neighborhoods. Transp. Policy 1996, 3, $127-141$. [CrossRef]

22. Cervero, R. Mixed land-uses and commuting: Evidence from the American Housing Survey. Transp. Res. Part A Policy Pract. 1996, 30, 361-377. [CrossRef]

23. Cervero, R. Jobs-housing balance revisited. J. Am. Plan. Assoc. 1996, 62, 492. [CrossRef]

24. Lee, C.; Moudon, A.V. The 3Ds+R: Quantifying land use and urban form correlates of walking. Trans. Res. Part D Transp. Environ. 2006, 11, 204-215. [CrossRef]

25. Meurs, H.; van Wee, B. Land Use and Mobility: A Synthesis of Findings and Policy Implications. Eur. J. Trans. Infrastruct. Res. 2003, 3, 219-233.

26. Bahadure, S.; Kotharkar, R. Assessing Sustainability of Mixed Use Neighbourhoods through Residents' Travel Behaviour and Perception: The Case of Nagpur, India. Sustainability 2015, 7, 12164-12189. [CrossRef]

27. Frank, L.D. Land Use and Transportation Interaction: Implications on Public Health and Quality of Life. J. Plann. Educ. Res. 2000, 20,6-22. [CrossRef]

28. Delso, J.; Martin, B.; Ortega, E. Potentially Replaceable Car Trips: Assessment of Potential Modal Change towards Active Transport Modes in Vitoria-Gasteiz. Sustainability 2018, 10, 3510. [CrossRef]

29. De Bourdeaudhuij, I.; Sallis, J.F.; Saelens, B.E. Environmental Correlates of Physical Activity in a Sample of Belgian Adults. Am. J. Health Promot. 2003, 18, 83-92. [CrossRef]

30. De Bourdeaudhuij, I.; Teixeira, P.J.; Cardon, G.; Deforche, B. Environmental and psychosocial correlates of physical activity in Portuguese and Belgian adults. Public Health Nutr. 2005, 8, 886-895. [CrossRef]

31. Geng, J.C.; Long, R.Y.; Chen, H.; Yue, T.; Li, W.B.; Li, Q.W. Exploring Multiple Motivations on Urban Resident' Travel Mode Choices: An Empirical Study from Jiangsu Province in China. Sustainability 2017, 9, 136. [CrossRef]

32. Joh, K.; Chakrabarti, S.; Boarnet, M.G.; Woo, A. The Walking Renaissance: A Longitudinal Analysis of Walking Travel in the Greater Los Angeles Area, USA. Sustainability 2015, 7, 8985-9011. [CrossRef]

33. Rodríguez, D.A.; Evenson, K.R.; Diez Roux, A.V.; Brines, S.J. Land Use, Residential Density, and Walking. The Multi-Ethnic Study of Atherosclerosis. Am. J. Prev. Med. 2009, 37, 397-404. [CrossRef]

34. Yang, Y.; Diez-Roux, A.V. Adults' Daily Walking for Travel and Leisure: Interaction Between Attitude Toward Walking and the Neighborhood Environment. Am. J. Health Promot. 2017, 31, 435-443. [CrossRef] [PubMed]

35. Mitchell Hess, P.; Vernez Moudon, A.; Logsdon, M. Measuring Land Use Patterns for Transportation Research. Trans. Res. Rec. J. Trans. Res. Board 2001, 1780, 17-24. [CrossRef]

36. Horner, M.W.; Marion, B.M. A Spatial Dissimilarity-based Index of the Jobs-Housing Balance-Conceptual Framework and Empirical Tests. Urban Stud. 2009, 46, 499-517. [CrossRef] 
37. Song, J.; Wang, R. Measuring the Spatial Dimension of Automobile Ownership and Its Associations with Household Characteristics and Land Use Patterns: A Case Study in Three Counties, South Florida (USA). Sustainability 2017, 9, 558. [CrossRef]

38. Belsley, D.A. Conditioning Diagnostics: Collinearity and Weak Data in Regression; John Wiley \& Sons: New York, NY, USA, 1991.

39. Crane, R.; Crepeau, R. Does neighborhood design influence travel?: A behavioral analysis of travel diary and GIS data. Trans. Res. Part D Trans. Environ. 1998, 3, 225-238. [CrossRef]

40. Song, Y.; Merlin, L.; Rodriguez, D. Comparing measures of urban land use mix. Comput. Environ. Urban Syst. 2013, 42, 1-13. [CrossRef]

41. Kockelman, K.M. Travel behavior as function of accessibility, land use mixing, and land use balance: Evidence from San Francisco Bay Area. Trans. Res. Rec. 1997, 1607, 116-125. [CrossRef]

42. Land, I.A.T. Enforcement Decree of The National Land Planning and Utilization Act. In 29395; The National Assembly of The Republic of Korea: Seoul, Korea, 2018.

43. Min, B. The Effects of Land Use Characteristics on Trip Patterns by Trip Purpose and Travel Mode. Master's Thesis, Korea University, Seoul, Korea, 2016.

44. Lavoie, M. Characterizing Land Use and Transportation for Transit-Oriented Development in the Montreal Metropolitan Region; McGill School of Urban Planning: Montreal, QC, Canada, 2012.

45. Clifton, K.; Ewing, R.; Knaap, G.J.; Song, Y. Quantitative analysis of urban form: A multidisciplinary review. J. Urban. Int. Res. Placemak. Urban. Sustain. 2008, 1, 17-45. [CrossRef]

46. Manaugh, K.; Kreider, T. What is mixed use? Presenting an interaction method for measuring land use mix. J. Trans. Land Use 2013, 6, 63-72. [CrossRef]

47. Duncan, O.D.; Duncan, B. A Methodological Analysis of Segregation Indexes. Am. Soc. Rev. 1955, 20, 210-217. [CrossRef]

48. Bento, A.M.; Cropper, M.L.; Mobarak, A.M.; Vinha, K. The effects of urban spatial structure on travel demand in the United States. Rev. Econ. Stat. 2005, 87, 466-478. [CrossRef]

49. Massey, D.S.; Denton, N.A. The Dimensions of Residential Segregation. Soc. Forces 1988, 67, 281-315. [CrossRef]

50. Park, G.; Choi, C. Influence of Neighborhood Land Use on Residents' Choices of Shopping and Leisure Facilities. J. Korea Plan. Assoc. 2012, 47, 249-263.

51. Seo, M.; Kim, S. An Analysis on the Relationship between Planning Elements of Urban Form and Travel Behavior CharacteristicsFocused on Planning Policy for the Green City by Size and Locations. J. Korea Plan. Assoc. 2011, 46, $223-244$.

52. Choo, S.; Park, S. Analyzing Spatial Distribution and Trip Generation Factors by Household Structure in Seoul. J. Trans. Res. 2013, 20,1-13. [CrossRef]

53. Min, B.; Lee, G.; Kim, S. The Effects of Land-use Characteristics on Trip Patterns by Trip Modes and Purposes. J. Arch. Inst. Korea 2016, 32, 77-87.

54. Hillier, B. Space Is the Machine: A Configurational Theory of Architecture; Space Syntax: London, UK, 2007.

55. Doreian, P. Estimating Linear Models with Spatially Distributed Data. Soc. Methodol. 1981, 12, 359-388. [CrossRef]

56. Doreian, P. Linear-Models wth Spatially Distributed Data-Spatial Disturbances or Spatial Effects. Sociol. Methods Res. 1980, 9 , 29-60. [CrossRef]

57. Moran, P.A.P. Notes on Continuous Stochastic Phenomena. Biometrika 1950, 37, 17-23. [CrossRef] [PubMed]

58. Florax, R.J.G.M.; de Graaff, T. The Performance of Diagnostic Tests for Spatial Dependence in Linear Regression Models: A Meta-Analysis of Simulation Studies. In Advances in Spatial Econometrics: Methodology, Tools and Applications; Anselin, L., Florax, R.J.G.M., Rey, S.J., Eds.; Springer: Berlin, Germany, 2004; pp. 29-65. [CrossRef]

59. Haandrikman, K.; van Wissen, L.J.G.; Harmsen, C.N. Explaining Spatial Homogamy. Compositional, Spatial and Regional Cultural Determinants of Regional Patterns of Spatial Homogamy in the Netherlands. Appl. Spat. Anal. Policy 2011, 4, 75-93. [CrossRef]

60. Dingil, A.E.; Rupi, F.; Stasiskiene, Z. A macroscopic analysis of transport networks: The influence of network design on urban transportation performance. Int. J. Trans. Dev. Integr. 2019, 3, 331-343. [CrossRef]

61. Liu, X.; Gong, L.; Gong, Y.; Liu, Y. Revealing travel patterns and city structure with taxi trip data. J. Trans. Geogr. 2015, 43, 78-90. [CrossRef]

62. Nuzzolo, A.; Comi, A.; Polimeni, A. Exploring on-demand service use in large urban areas: The case of Rome. Arch. Trans. 2019, 50. [CrossRef] 